\title{
EMERGING SECURITY RISKS OF E-HAIL TRANSPORT SERVICES: FOCUS ON UBER TAXI IN NAIROBI, KENYA
}

\author{
Cosmas Ekwom Kamais \\ Department of Peace, Security and Social Studies, Egerton University, Kenya
}

\begin{abstract}
This study attempted to examine the emerging security risks brought about by the e-hail taxi mode of transportation. It argues that despite the fact that the security risks associated with traditional taxi transportation still apply to e-hail taxi services, there are emergent risks that are unique to the app-based taxi hailing services. It further contends that as evidenced by the reactionary way of addressing security issues arising form usage of the service, it is clear that security was not a factor during conceptualisations, development and operation of the app-based taxi service. The study conducted a survey of uber customers and drivers in Nairobi County Kenya, and data was collected from 400 respondents with $85 \%$ response rate. Majority of the respondents indicated that they somewhat often (32.23\%), agreed that Uber is more convenient (58.76\%), indicated that Uber offers more business and job opportunities (86.46\%). Despite the positive opinions by the respondents, $65.31 \%$ opined that Uber portend security risks. Majority indicated that the following risks are likely; abductions (40.82\%), carjacking (40.82\%), sexual harassment (38.14\%), murders $(35.71 \%)$, robbery $(41.84 \%)$ and burglaries (34.69\%). However, a majority of $28.57 \%$ thought that hackings into sensitive customer and company data was less likely. Furthermore, $57.14 \%$ of the respondents felt that the regulatory framework for appbased taxi hailing system were not sufficient to guarantee safety and security while $75.51 \%$ were optimistic that the e-hail transport industry will take meaningful security mitigation measures from the lessons they have learned. Finally, 92.93\% of the respondents felt that government authorities should do more in regulating app-based services such Uber while $85.86 \%$ opined that founders and managers of ehail taxi services should be held responsible for security lapses. The study recommends that a review of existing traffic laws and criminal laws be done to take care of the emerging security risks associated by app-based service providers.
\end{abstract}

\section{Keywords}

e-hail Taxi, app-based, Uber, Transport, Security Risks, Convenience, Information Technology, collaborative economy.

\section{BACKGROUND}

Developments in the transport sector has greatly improved the travelling experience and enhanced convenience. Integration of technology has revolutionized how transport, especially Taxi, is operated and experienced. The customer can order a ride and be picked and a place of choice. With such advancements, scholars and pundits have tended to focus on economic potential with a cursory glance at the regulatory framework as a reaction to disputes [1]. Unfortunately, this has left the security aspects almost completely ignored despite the various reported security incidences related to transport access systems like Uber, Lyft among others [2]. Security risks include sexual harassments, murder, kidnappings, hate crimes hacking into sensitive customer and organisation information among others. 
Advancements developments in the transport sector has made life easier in terms of accessing locations for various reasons ranging from business to leisure. Over the years, innovation has sought to further improve this convenience. Evolution of information technology has tremendously enhanced such innovation for convenience in the world transportation sector. From the from trekking and use of animals or dhows to the invention of the first car by Daimler, transport means has undergone tremendous development [3]. The need to have transport vessels control by use of information technology has exceedingly taken precedence over the need to develop faster cars for instance. With these developments come great potential for economic growth, convenience and luxury. However, challenges also abound with each improvement towards advancements in the transport sector.

The world is becoming accustomed to breath-taking technological advancements in the in transportation. Some companies are even experimenting with self-driving cars and prototypes are already being tested despite various setbacks. Environmental conservation has required that vehicles are modified to emit less carbon or even eliminate carbon emissions. This has seen innovations of electric engines, gas engines, and even thoughts of making engines that can run onoxygen are being explored. These innovations will surely make a contribution in reducing carbon emissions and the impact of global warming. However, the problem is a wider than vehicular carbon emissions and it spans to other large emitters in sea transport, air transport and even the industries.

Besides the innovations in the vehicular contraptions, service providers have seen the need to make their services easily available to the consumers in a business model termed as 'sharing', or 'collaborative' economy, which is typified by new app-enabled business enterprises linking up consumers with service providers of many kind [4]. To facilitate this booking services have crossed from the traditional office visit and receipting system to the online booking and payment platforms in the various service providers' websites and portals in what some scholars have referred to as crowd capitalism or platform-based capitalism [5]. The competition in the taxi transportation sector has made innovation move a notch higher in terms of availing booking services to the customer. Development of applications such as Uber, Lyt, Taxify and others have facilitated taxi service providers achieve this through a system of e-Commerce/ collaborative sharing in which people with surplus energy or assets can make money by assisting others with their skills through an app based intermediary for a commission [4].

\section{Statement of the problem}

Developments in the transport sector has led to tremendous benefits in the transport sector itself as well in industry, business and world economy a whole. Technology is becoming more integrated into innovations in the sector. With this integration comes risks of various nature critical of which is security risk. As in any business undertaking, security is central to all activities and if not considered well leads to devastating losses in business bottom line, reputation, and even lives.

Whereas security experts recommend that security must be a consideration in all phases of the business right from conception and design, most of the time it is ignored. Security plans are usually a hard sell to management since the costs of instituting security measures are mostly high [6]. As such, security is often considered as a function of management that does not give direct returns and thus categorised as a liability to the business. Business managers will look for any ways to cut down on operating expenses and security is usually vulnerable to such austerity mentality. Even at deliberations and business developments, security gets downplayed or ignored all together. Regulatory frameworks are often weak and lacking in foresight of all the possible risks including business risks $[1 ; 7]$. This exposes business ventures to security risks. 
Information technology adds the cybersecurity dimension to traditional physical security. This is true for Uber and other e-hail taxi services.

With convenience brought about with such innovations, there comes an even great possibility of security risks. The fact that they are already being reported in the form of abductions, killings, theft of property, compromise of sensitive personal or corporate information among others indicates existence of weak security measures to mitigate such risks or at worst, inadequate appreciation of the security risks during development of the Uber technology. Similar, scholars have not been keen to research on e-hail taxi phenomenon and suggest informed steps to mitigate on negative effects while maximizing on the benefits.

Most authors have explored many aspects of the app-based service provision, Riley [4] looked at pertinent labour protections issues more so of uber drivers on whether they should be treated as employees, and enjoy all the protections available. He recommended that a better solution would be the introduction of a special scheme providing protections similar to those available to other small business workers in special kinds of commercial relationships. Ignoring security risks concerns, Geist [1] delved into the threat that technology-based ventures like Uber,Lyft, Amazon, Netflix, among others pose to the going concern of the traditional business models and thus the need for regulations to address the concerns by examining the intersection between the sharing economy and international trade agreement. With most other scholars such as Calo \& Rosenblat [3], Cassar \& Meier[8].Escande-Varniol[7],Tucker[5] among others, exploring nonsecurity aspects of app-based business models especially in the transport sector, there arises a gap which this study sough to fill by forming the foundation on which to spur further research into e-hail taxi and other developments in economic sectors with a keen interest on potential security risk.

\section{Research Objectives}

The paper sought to achieve the following objectives:

i. To explore the evolution of Uber e-hail Taxi Services.

ii. To assess the comparative benefits of Uber e-hail Taxi Services.

iii. To analyse the emerging challenges in Uber e-hail Taxi Services.

\section{REVIEW OF LITERATURE}

\section{Evolution ofUber e-hail Taxi Services}

Companies such as Uber and Airbnb are less than ten years old, yet they have had a remarkable disruptive effect on the economy and long-standing regulatory approaches [1]. Uber, based in San Francisco, currently operates in 662 cities and eighty-two countries around the world [9]. The service provider offers several tiers of service, ranging from upscale town cars with professional drivers (Uber), to low-cost privately owned "regular cars" driven by amateur or part-time drivers. Estimated revenue for the company is more than $\$ 5$ billion annually [8].

According to Blystone[9], Uber's disruptive technology, explosive growth, and constant controversy makes it one of the most fascinating companies to emerge over the past decade. For a period of about ten years, the company has tremendously grown to become one of the highest valued private start-up company in the world. This is despite facing turmoil on the stock exchange due to controversies about its security, finances, human resource management, among other factors. This turmoil has cost uber in terms of valuation. It is estimated that in the 2018 funding round, Uber experienced as slump with its valuation dropping from $\$ 70$ billion to $\$ 48$ 
billion [9]. However, some economic pundits such as Jalloh [10] are upbeat that despite the lower valuation, today is valued more than the market cap of Ford Motor Company and General Motors Company.

As many other start-ups, including in the tech industry, the story of Uber seems to come from humble beginnings. According to accounts by Blystone[9], Uber's story began in Paris in 2008. It is reckoned that two friends, Travis Kalanick and Garrett Camp, were attendingan annual tech conference when the duo were not unable to get a cab on a cold winter night. The initial thought is said to be an idea for a timeshare limo service that could be ordered via an app. After the conference, the entrepreneurs went their separate ways, but when Camp returned to San Francisco, he continued to be fixated on the idea and bought the domain name UberCab.com.In 2009, Camp began working on a prototype for UberCab as a side project [9]. By summer of that year, Camp had persuaded Kalanick to join as UberCab's 'Chief Incubator'. Theservice was tested in New York in early 2010 using only three cars, and the official launch took place in San Francisco in May. Ryan Graves, who was Uber's General Manager and an important figure in the early stages of the company, became CEO of Uber in August 2010. In December 2010, Kalanick took over again as CEO, while Graves assumed the role of COO and board member [9].The ease and simplicity of ordering a car fuelled the app's rising popularity. With the tap of a button, a ride could be ordered; GPS identified the location and the cost was automatically charged to the card on the user account. In October 2010, the company received its first major funding, a $\$ 1.25$ million round led by First Round Capital [9].

It is further noted that, in October 2010, the company received a cease-and-desist order from the San Francisco Municipal Transportation Agency due to the use of the name UberCab [9]. This prompted the change of name to Uber and the subsequent buying of the Uber.com domain name from Universal Music Group.It is reported that in early 2011, the company raised an estimated $\$ 11$ million in a round of funding led by Benchmark Capital [3]. This enabled Uber to expand to New York, Seattle, Boston, Chicago, Washington D.C. as well as abroad in Paris. At the December 2011 LeWeb Conference, Kalanick announced that Uber raised \$37 million funding from Menlo Ventures, Jeff Bezos, and Goldman Sachs [9]. In 2012, the company broadened its offering by launching UberX, which provided a less expensive hybrid car as an alternative to black car service.

During its expansion, Uber has met fierce resistance from the taxi industry and government regulators. As part of their strategy to mitigate the opposition, the company hired David Plouffe, a high-profile political and corporate strategist who worked on Obama's 2008 presidential campaign [2]. In 2014, taxi drivers in London, Berlin, Paris, and Madrid staged a large-scale protest against Uber [9]. The dispute between traditional Taxi companies and Uber has manifested on several occasions. Taxi companies have claimed that Uber creates unfair competition since it avoids expensive license fees and bypasses local laws. These squabbles led to filling of a case on the matter in Europe's top court which was heard in December of 2016. Subsequently, Uber lost its license to operate in London where the company had 40,000 registered drivers in October 2017. In their submissions, the Transport for London (TfL) argued that Uber was unfit to hold a license, while Uber countered that the Mayor of London had caved to pressure and persuasions from people keen to limit the consumer's choice. On June 26, 2018 Uber got a reprieve when a London judge overturned the ban [9]. This development enabled Uber to operate under a 15-month license along with conditions. According to Bystone[9], the year 2017 was also a rough year for Uber with troubles beginning in February when a former female Uber engineer ousted the company for its sexist culture in a 3,000-word blog post. It was alleged that Uber's corporate culture was highly hostile, sexist and quite offensive to most people. The post quickly went viral and a number of high-level employees were let go or resigned for reasons relating to the allegations in the following months. Following the blog post, 
the board called for an internal investigation which became known as the "Holder Investigation" resulting in 47 recommendations intended to improve the culture and work environment, and, according to Uber, the firing of more than 20 staff members [9].

The controversies in Uber's operations seemed to by developing each day they surmounted a previous challenge. For instance, in New York, it surfaced that Uber had mistakenly charged drivers commission based on pre-tax earnings as opposed to after-tax earnings [9]. This effectively meant that the affected drivers lost tens of millions of dollars.In its defence, Uber argued that it was an accounting error and assured the affected drivers that it was committed to paying them back in full as quickly as possible. With what appeared to be a strained relationship, the driver's advocacy groups claimed that for some time that Uber had been evading tax at the expense of its drivers[11]. This was a counter argument for the reasons why the alleged accounting error had been executed by Uber against the victim drivers.

Being a tech app-based intermediary, Uber works like a driver dispatch tech office as juxtaposed to traditional taxi companies. In its price management, it is observed that Uber uses an automated algorithm to increase prices based on supply and demand in the market [9]. This was evident on New Year's Eve of 2011 where prices soared to as high as seven times standard rates this attracting negative feedback from customers. The same situation repeated itself in December of 2013 snowstorm in New York when hiked prices triggered outrage from Uber users. The negative customer sentiments on price hikes during peak seasons, and occasions when demand rises, has made Uberto cap surge pricing especially during bad weather conditions in New York City.

In a bid to beat competition, diversify operations and attract more customers, Uber developeda merchant delivery program for food called Uber Eats besides offering UberPool. These additions allow Uber drivers to pick up multiple customersin one ride that making ita cheaper option compared to other variant services of Uber such as UberX and UberBlack [3]. In 2017, the company, in partnership with Barclays, rolled out a co-branded rewards credit card in the U.S. The Uber Visa Card reportedly will be free and come with a $\$ 100$ starting bonus [10]. Furthermore Blystone[9] noted that on July 9, 2018, Uber was investing in the electric scooter rental company, Lime, in collaboration with Alphabet Inc.'s Google Ventures. These lightweight scooters are available for rent all over cities, as customers leave them on the sidewalk for the next rider, making for a convenience and clean energy-based business model [12]. Uber made similar efforts with the start-up JUMP Bikes before acquiring the business for reportedly close to \$200 million in April 2018 [13]. All these efforts are geared towards improving customer satisfaction and beating competition. However, conspicuously lacking in Uber's evolution and developments is security risk mitigation strategies. Despite having numerous reported and conformed security lapses such as the 2016 hacking and data compromise, the story of Uber has mostly been about more of beating competition and rectifying other non-security controversies. This leaves one to desire as to what exactly is the company's security strategies in the face of abductions, murder, carjacking, burglary among others that are perpetrated by Uber drivers, or against Uber drivers [14].

Uber was officially launched in Nairobi Kenya on 23 January, 2015 with an initial 20\% discount on fares amounting to about Kshs. 164 per $\mathrm{Km}[15]$. The taxi service provider initially faced resistance from the existing taxi drivers who were reeling under the lack of customers and now had to contend with a new entrant in the market. The resistance escalated to open hostility when one uber taxi driver was badly beaten and his taxi burned by suspected taxi operators who were opposed to uber based taxi operations[16]. Despite these initial challenges, Uber tried to engage the dissenting entities to arrive at an understanding on operations. The company also went ahead to expand to other towns such as Mombasa, Kisumu, Eldoret, Nakuru among others. 


\section{Comparative Benefits of Uber Taxi Services}

As in many other businesses, the service providers have sought to go to the customer as opposed to the customer going to them. Customers can now choose their ride, have the taxi pick them at their location, and pay on arrival at the destination. App- based service providers especially in the transport sector have proven cheaper and convenient as compared to other transport providers. Although no figures have been put forward,scholars have noted that many young people use Uber because it is cheaper than hiring a taxi [4]. Being convenient, clean and costeffective, the Ubers and Lyfts among other Transportation Network Companies(TNCs), have become the primary means for most people get from one point to the next.According to Jalloh[10], instead of chasing down a taxi on a street; or calling and waiting half an hour for a dispatch taxi, e-hail app users are able to hail a car from any location using internet connected smartphones and have it arrive within minutes. Payment for the service is also convenient since customers can pay using Mobile money services like M- Pesa, or credit card that is linked to the e-hail Uber account. However, some scholars such as Tucker [5] have argued that there is no significant difference between Uber app model and the traditional taxi dispatch services. The Uber app is merely a software platform that enables Uber drivers to reach that public, just as telephone and radio dispatch services enabled traditional taxi drivers to connect with customers [5]. However, the app-based system seems to be preferred due to its convenience and the possibility of sharing you ride information with friends on the network for safety and security purpose.

Uber and other e-hail TNCs have developed a commendable reputation of providing Professional Services. Due to competition and regulations, most Uber vehicles are of later models, clean and comfortable. For instance,in major cities like New York where the taxi industry is regulated, cars are required to be new, well maintained and chauffeured by professional drivers who have proper commercial insurance coverage [3]. E-hail taxi service providers operate in a way that when a driver accepts an assignment, passengers are able to track a driver's position and route, and they can communicate with the assigned driver if necessary. A driver only learns the passenger's destination when the journey starts thus eliminating the problem of being refused access to a taxi because the passenger wishes to travel to undesirable parts of town or hiking the fare as a way to discourage the customer from taking the ride. Furthermore, Riley [4] notes that Uber uses a rating system to determine which drivers are offering satisfactory services to the customers. Unprofessional drivers are weeded out because passengers get to rate the driver's performance with those consistently receiving low rating being forced out of Uber Taxi services.

It has also been observed that some safety considerations are comparably better for drivers working with Uber or other e-hail services. For instance, because the transaction is cashless, a driver does not face unpaid fares or need to carry a sizeable amount of cash that might entice a robber [10]. Rude, aggressive, and disruptive passengers are eliminated since the drivers can also rate their customers. Consistently low ratings or reports of unsafe behaviour toward drivers can cause deactivation of a customer's account [17]. Uber services are also available around the clock making it suitable for emergency situations or those who patronize entertainment joints late into the night. It is noted that unlike yellow cab taxi drivers who work 12-hour shifts, or black car drivers who are scheduled by dispatchers, Uber and other e-hail drivers enjoy greater freedom and flexibility [5]. Drivers can $\log$ in and out of the system anytime and choose their own hours. Drivers can avoid expensive taxi rental leases by acquiring their own vehicles. This means more profit for drivers, all else being equal. Drivers are also spared the stress caused by favouritism and office politics because the app renders dispatchers irrelevant. 
Besides the benefits to the customers who use e-hail taxi services for purely transportation, innovations such as Uber has enhanced job creation for drivers and increased income for drivers who would otherwise park their vehicles in the Taxi ranks for extended periods of time. Its has been noted that the sharing economy has attracted increased attentiondue to disruption of longstanding, well-established market sectors;and also, by creating new opportunities that threatens powerful economic interests [1]. It has been noted that the gains of uber services is double of those other non-flexible arrangements [8]. Research findings have shown that by the end of 2015, the collaborative economy was valued at \$504 Million and about 45, 000 people benefited from it as source of supplementary income [18]. Such advantages lead to growth in the GDP and per capita income.

home and was later found dead [21]. On the hand, Uber drivers have fallen victim to nefarious individual who disguise themselves as passengers. Instances of drivers being hijacked, killed, vehicles stolen has been on the rise. In May 2014, Uber driver reportedly went missing in the USA and three years later his vehicle was found abandoned [22]. According to NBC news, in the first week of January 2019, an Uber driver disappeared in Washington DC af

\section{Emerging Security Risks in UberTaxi Services}

With convenience and business potential, Uber and similar service providers have posed regulatory controversies and security challenges to both the taxi drivers and passengers. It is noted that risk managers could be underestimating the additional liability exposures that come with employing transport networking companies [19]Numerous incidences have been reported or confirmed involving carjacking and even murder of taxi drivers and motorbike riders [2].

There have been instances of hate crime being perpetrated by individuals disguised as uber taxi drivers [14]. Cases of passengers getting into wrong vehicles thinking it is their ordered Uber taxi have also surfaced especially in the USA. As this could appear a mistake at face value, a critical security mind will read mischief in the form of a possible hacking of the traffic between the customer and the genuine Uber Taxi. These passengers have ended up being raped, killed or both. However, according to an editorial by The Harvard Crimson [17], Uber has made some attempts to address such challenges. This is througha partnership between Uber and emergency response-focused start-upRapidSOS leadinga recent implementation of a "911 Assistance" feature. The Crimson Editorial Board [17] indicates that the safety response feature included in the Uber's new safety toolkit, enables users in Cambridge to contact police without exiting the app thus giving emergency responders earlier warning in the event of any security issues. While this is a good effort in improving safety, it is not sufficient in the face of security concerns raised against the Uber app.More so, the measure is reactive in orientation, rather than being proactively developed through a Security Risk Analysis(SRA) process as required by safety and security standards [6].

Passengers facethe risk of fake and predatory drivers posing as Uber taxi drivers. Being based on IT platforms, and operated through mobile phones and electronic gadget whose security is weak at best, the possibility of hacking by nefarious elements is an ever present. According to business insider, Uber updated its software at the end of 2016, which triggered controversy for allowing it to track locations of users well after their ride had ended [2]. A subsequent analysis of the flow of data in and out of the updated Uber app, by tech security firm Appthority, indicated that it displayed a range of risky behaviours that were more of a concern than in previous versions. A major worry was that the newer versions of the popular ridesharing app no longer enforced an encrypted connection, through secure sockets layer (SSL) technology, to send data back and forth thus exposing it to snooping by third parties. Such scares have often been expressed by security analysts. Thom Rickert, VP and emerging risk specialist at Trident Public Risk Solutions observed that Protection of PII (personal identifiable information) is a risk 
that is unique to app-based service providers and that it is a nuance that does not exist with other types of traditional transportation systems [19].

Sensitive information about key business personalities who use Networked transport services is more at risk than ever. Integrating with a rideshare platform creates another point of entry into a company's corporate network. This exposes confidential company data to theft and increases vulnerability to a malware attack. In 2017, Uber launched a B2B platform (Uber for Business) designed to allow companies to manage rides taken by their employees or ordered for customers or partners [2]. The program allows approved rides to be automatically charged to the company account and provides detailed records of who took the ride, to where and at what time. By linking directly to a corporate account, the platform exposes business users to direct financial theft. It has been established that Uber has the ability to track location not only for C-level executives but also for salespeople, developers and other enterprise employees whose location could signal some activities that they don't want revealed for business reasons [2]. Employee location is very important business information and it becomes more valuable when other contextual data are added. For example, Uber can access not only the location of a meeting, but also the meeting agenda, by accessing calendar, and the meeting attendees and their contact information, by accessing address book.

In the year 2016, a massive data breachoccurredin the Uber app occurred affecting about 57 Million users. According to Uber CEO, Dara Khosrowshahi, the data breach affected the names and driver's license numbers of around 600,000 drivers in the United States; and some personal information of 57 million Uber users around the world, including the drivers [20]. This information included names, email addresses and mobile phone numbers. To address the cybersecurity challenges, and in implied admittance of guilt, Uber made the following recommendations for customers;

"...the Uber app can be blacklisted for all users or only for privileged users or another select group that may be more high-risk targets. If an enterprise security team chooses not to blacklist the Uber app, they can educate employees to turn off location services for the app. Uber will still function, the user just has to type in the pickup address. Users may choose to do that anyway to avoid the post-ride location tracking. As a general best practice, enterprises should educate their employees that it is best not to give access to apps which request access to another app unnecessarily. If access has already been given, the user can revoke the access by going to the user's settings page on the Uber website. '[20].

Some cases have cases have involved supposedly genuine drivers going rogue and turning on their customers, raping, kidnapping them for ransom or even killing them. In the USA there have been various incidents of passengers disappearing after procuring Uber services. Forinstance, a University of South Carolina mistakenly boarded a cab she thought was a Uber she had ordered but never arrived ter picking a passenger [23]. In Kenya, it was reported that a Uber taxi driver was beaten and his car torched in the year 2016 [16]. This seemed to be protest action by traditional taxi drivers who claimed that entry of Uber services into the Kenyan taxi market in 2015 was bringing undue competition. In response to such Uber has made promises to review and strengthen their security measures. Such measures include introduction of a feature that would help protect both riders and drivers in Kenya from the risks of fraud and theft by requiring drivers to periodically take selfies in the Uber app accepting rides [24]. The logic is that incase the photo of the driver does not match the one registered to their account, then that account is blocked. However, the sufficiency of such measures are still questionable in the phase of image manipulation applications such as photoshop. 
Whenever passengers are picked from their residences and dropped off at their destination, nefarious Uber drivers are able to make an assessment if the security state of the residence and whether it is left unattended after the customer leaves. This poses another security risk where properties are exposed to potential burglars masquerading as Uber drivers. Such can be a motivative factor for a criminal driver to strike a vulnerable target such as an unattended residential house and steal valuables. Such situation presents classic ingredients for crime to occur as espoused in the 1979 Routine Activity Theory of Felson and Cohen where a property's able guardians become absent and thus an opportunity is created for a willing burglar with means to strike [25]. An example of such incident is was reported by the Huffington post on 10 April 2019. The report indicated that, after dropping his customers to the airport, a Uber driver on various occasions came back to the homes of the customers, broke into them and stole valuable items [26]. Although the driver was later apprehended by police, this exposes a failing by background checks which Uber has limitations on, thus leaving the customers at the great risk of dealing with criminal elements in the guise of Uber drivers. Such failings have led to a numerous incidence of sexual assault cases against Uber passengers. For instance, between July 2013 and July 2016, there were approximately 140 sexual assault allegations against Uber and Lyft passengers perpetrated by the drivers in the USA, UK, Australia and China [27]. This is as compared to only five reported incidences of Kidnapping of Uber drivers during the same period.

Governments have recognised the need for some regulation the collaborative economy sector, with caution that new regulation should not strangle innovation and forfeit all these coveted economic benefits [4]. However, it has been noted that, most regulatory initiatives have focused on issues consumer protection and risks of unfair competition with established service providers. In Australia for instance, Riley [4] notes that, the Road Transport (Public Passenger Services) (Taxi Industry Innovation) Amendment Act 2015 introduced amendments to the Road Transport (Public Passenger Services) Act 2001 in a bid to ensure that the new passenger transport services providers such as Uber and Lyft are regulated alongside the taxi hire car industries in the interests of passenger safety, by ensuring the registration and accreditation of drivers. However, whereas the acts seem to cover normal road safety concerns, it ignores issues of security issues such as vetting of service providers more so the drivers. The regulations also ignore the fact that app-based transport service provision brings about issues of cyber security which the tradition transport regulations may not cover.

In Kenya, the law governing traffic conduct is contained in the Traffic Act, 2016 Chapter 403, laws of Kenya (which was revised in 2018). While the act considers most aspects relating to traffic regulations, it does not have a provision for app-based system of procuring/ hailing transport, especially on apportioning liability in case of security mishaps. While this can be considered to be taken care of in the Kenya Penal Code of 2012, Chapter 63 Laws of Kenya (revised in 2014), such cases are likely to be thrown out based technicalities since Uber in itself is an in itself cannot do background check and does not assume liability for the conduct of drivers using the app despite instituting a raft of safety measures.

\section{Conceptual Framework}

The paper conceptualizes the relationship of factors in a atom nucleus model. Security forms theproton core around which the other developmental, and operating factors must revolve around as wold the electrons. That relationship is as depicted in the security atom model below: 


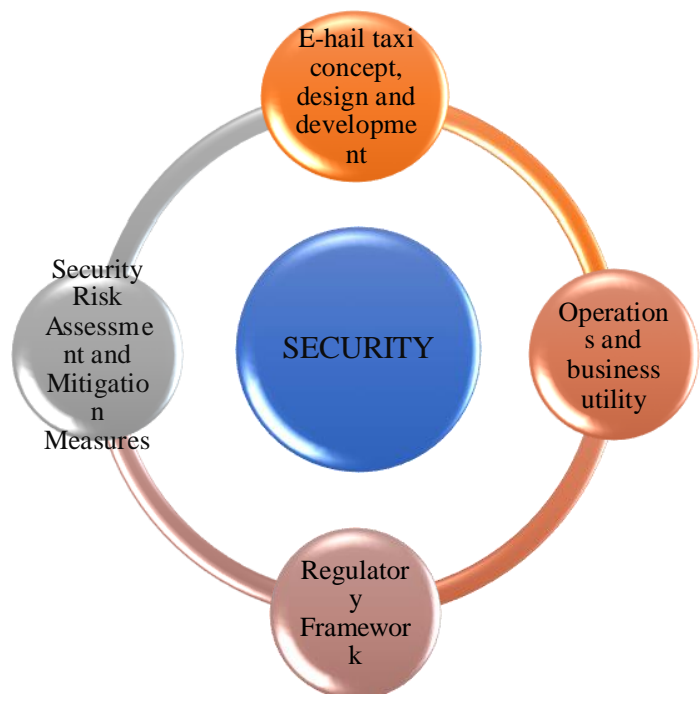

Figure 2.1: Security AtomModel (Author)

From figure 2.1 above, security and its considerations form the core around which other concepts have to be developed. Right from the conceptualisation and design of e-hail taxi technology, business utility of e-hail taxis, through to development and approval of the regulatory framework, and security risks assessments and mitigation measure, security considerations must be the anchor of them all. Virtually all ventures are fraught with risks of various kinds. Most critical of these risks are security related since they can unhinge an undertaking or even lead to catastrophic outcomes. The security atom,as the author conceptualises it, underscores the central role of security in any entrepreneurial undertaking. Just like at the protons form the nucleus of an atom, security is at the core of any venture. The main and supporting concepts through the lifespan of the venture will revolve around security considerations just like electrons revolve around the nucleus in an atom. Ignoring security considerations from design, operation and termination of a business undertakings is a gross mistake that often leads to devastating results.In the traditional conceptual framework, security is the independent variable while the dependant variables are; e-hail taxi conceptualization and developmental processes, operation and business utility, regulatory framework, and security risk assessment and mitigation measures. Whereas the model can be adapted to any business activity by substituting the surrounding factors (electrons) with those particular to a business, the core represented by security cannot be substituted.

\section{Methodology}

The study used exploratorysurvey design. Exploratory research, also known as formulative research studies, are aimed at formulating a problem for more precise investigation or of developing the working hypotheses from an operational point of view [28]. The major emphasis in such studies is on the discovery of ideas and insights. The research problem for formulative studies is broadly defined initially and then it is transformed into one with more precise meaning but where facts may necessitate changes in the research procedure for gathering relevant data [28]. Since Uber is a relatively new venture and more so its security risks aspects have not been researched on, this design is there suitable for exploring this aspect and forming a foundation for further studies/research.

The target population for this study was 4,556,381 residents of Nairobi City County, Kenya. A sample size of 400 respondents was drawn using Yamane formula on sample size. Purposive sampling was then used to select Uber drivers and customers. Data collected using 
questionnaire with clarification afforded to respondents by trained research assistants. The results and discussion are as presented in section 4.1.

\section{SUMMARY FINDINGSAND DISCUSSION}

\section{Summary Findings}

The Figures below presents that findings on various aspects ofcustomer use of uber services and their opinions. They range from frequency of use, opinion on convenience, whether uber offers more business and employment opportunities, whether Uber taxis portend security risks, likelihood of certain security risks when using uber taxi services, whether existing regulations on Uber Taxi services are sufficient to guarantee security of customers, whether e-hail taxis services can take reasonable measures to self-regulate, opinion on whether the government agencies need to do more to regulate Uber Taxi services and whether founders and managers of e-hail taxi services should be held accountable for security lapses.

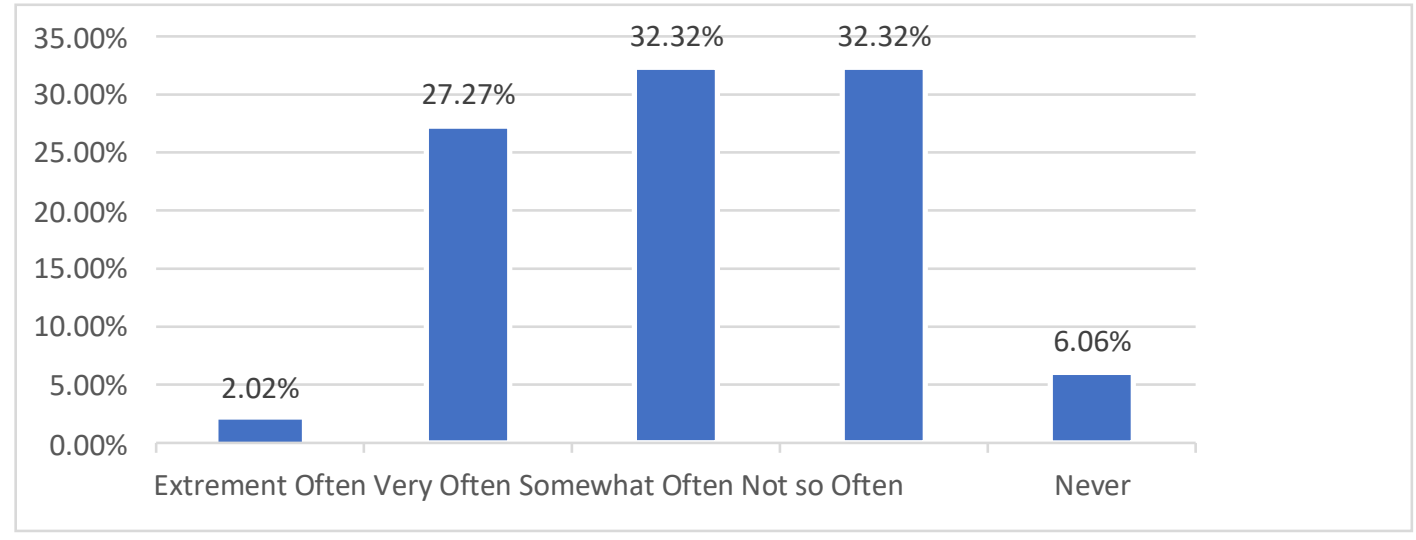

Figure4.1: How often respondents used Uber Taxi

In figure 4.1 above the $27.27 \%$ of the respondents indicated that they used Uber Taxi services very often while $32.32 \%$ indicated they used Uber Taxi services somewhat often. A similar percentage indicated that they do not often use Uber Taxi services while $2.02 \%$ and $6.06 \%$ indicated that they extremely often use Uber Taxi services and never use Uber Taxi services respectively.

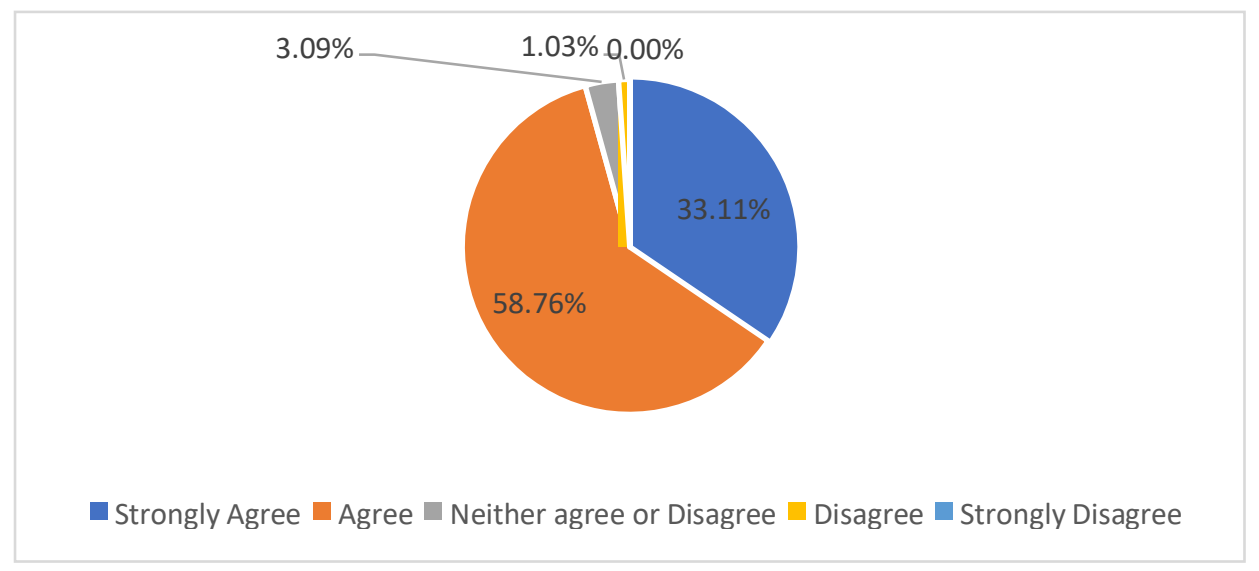

Figure 4.2: Convenience of Uber Taxi Compared to other Taxi Service Providers 
Figure 4.2 above indicates the perception of the respondents about the convenience of Uber Taxi Services as compared to other traditional Taxi service providers. A majority of the respondents $(58.76 \%)$ agreed that Uber Taxi is comparatively convenient while $33.11 \%$ strongly agreed. $3.09 \%$ of the respondents were undecided on whether Uber Taxi is comparatively convenient while $1.03 \%$ disagreed.

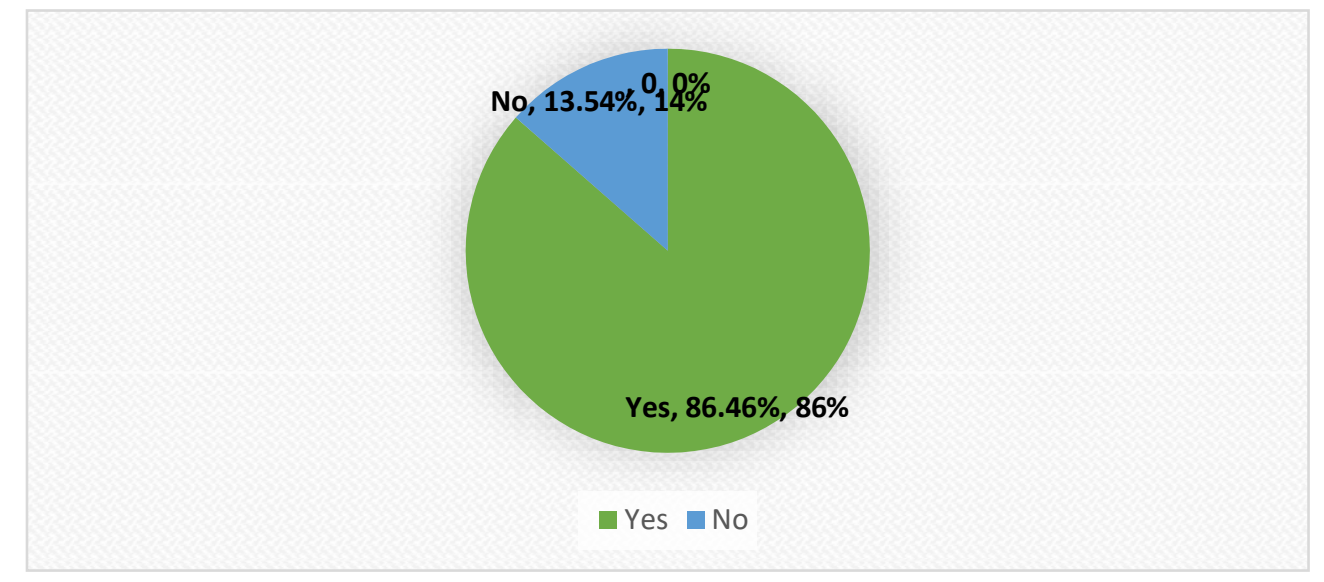

Figure 4.3: Uber offering Business/Employment Opportunities

Figure 4.3 above presents the respondents opinion on whether Uber Taxi services offer business and employment opportunities. Majority of the respondents (86.46\%) replied in the affirmative while $13.54 \%$ opined that it does not offer more business and employment opportunities.

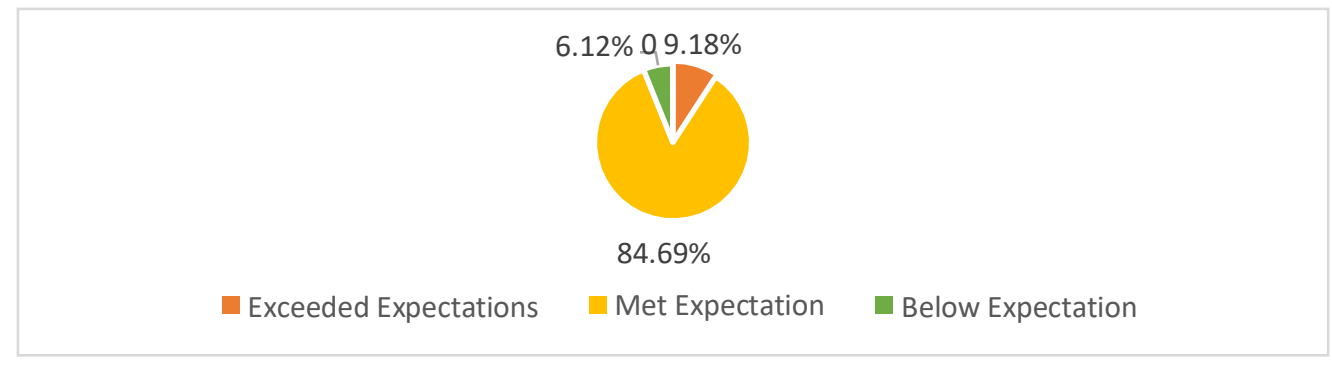

Figure 4.4: Uber Taxi Meeting Customer Expectations

On whether Uber Taxi services met customer expectations Figure 4.4 above indicates that $84.69 \%$ felt that Uber Taxi services met their expectations while $9.18 \%$ felt that it exceeded their expectations. However, $6.12 \%$ of the respondents felt that Uber taxi services were below their expectations.

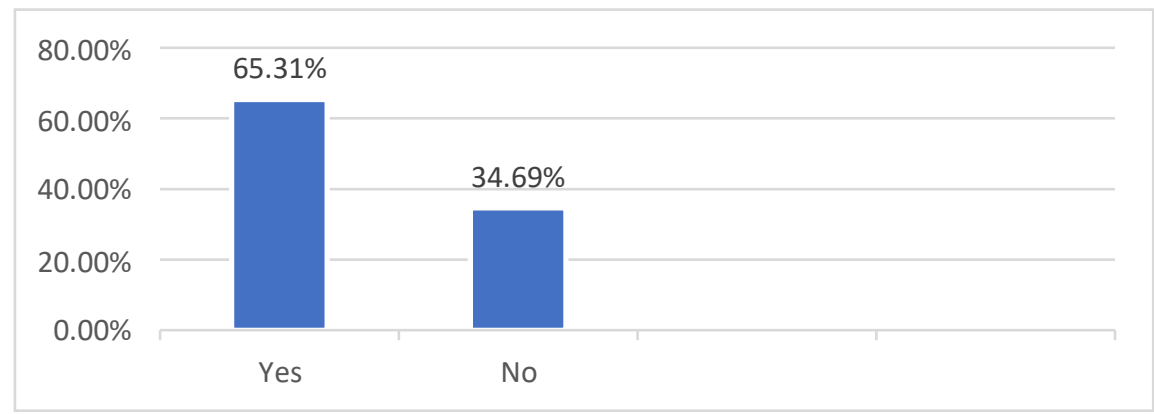

Figure 4.5: Uber Taxi Services Portend Security Risks 
International Journal of Security, Privacy and Trust Management (IJSPTM) Vol 8, No 3, August 2019

On whether Uber Taxi services portend security risks to drivers and customers, Figure 4.5 above indicates that $65.31 \%$ of the respondents agreed that Uber Taxi services portend security risks while $34.69 \%$ of the respondents disagreed.

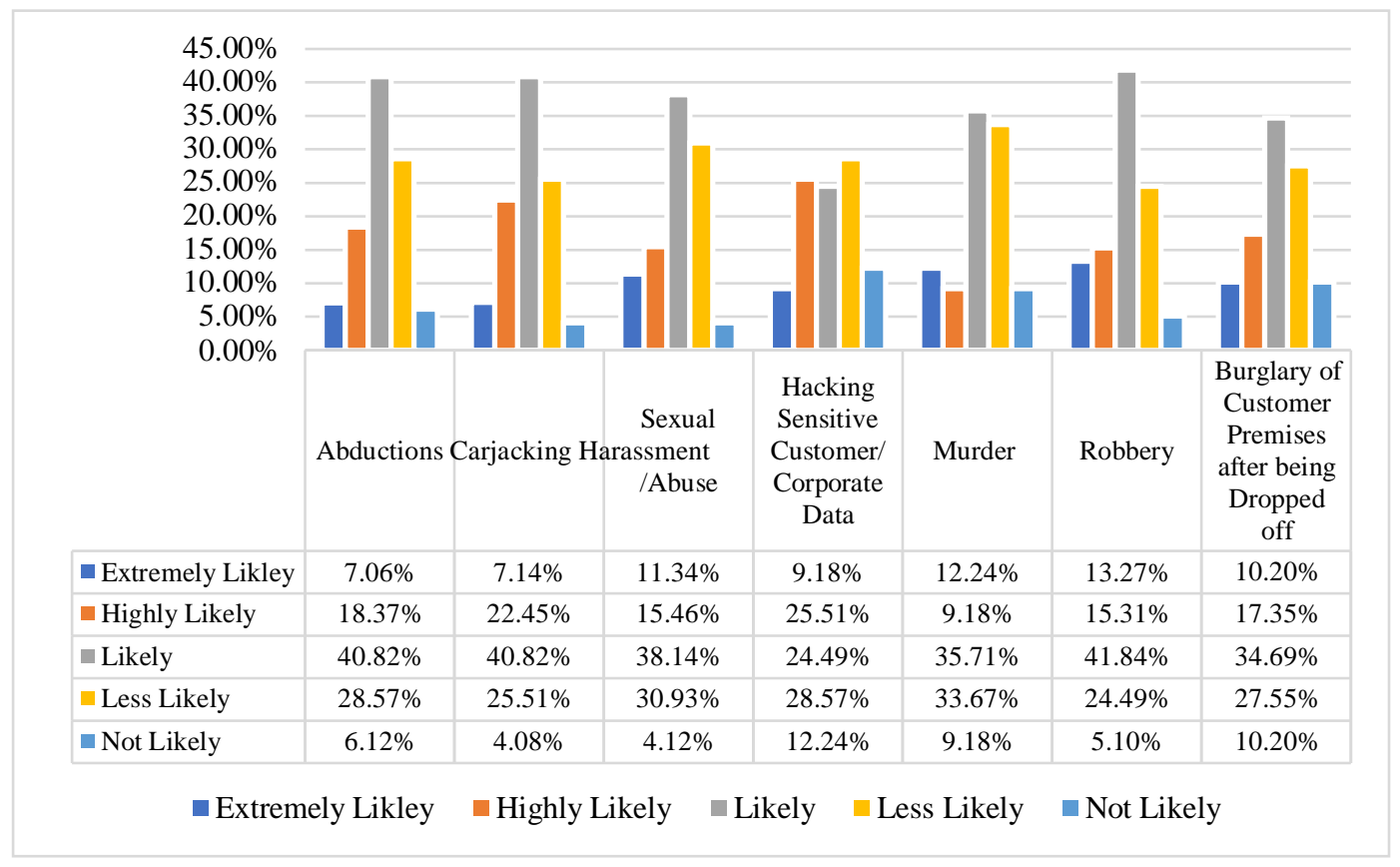

Figure 4.6: Likelihood of Security Risks to occur when using Uber Taxi

The respondents were asked to give their opinion on the likelihood of certain security risks occurring to either Uber drivers or customers and the responses are as indicated in Figure 7 above. The security risks included Abduction, carjacking, sexual harassment/abuse, murder, robbery, and burglary. In summary, Majority indicated that the following risks are likely; abductions (40.82\%), carjacking (40.82\%), sexual harassment $(38.14 \%)$, murders $(35.71 \%)$, robbery $(41.84 \%)$ and burglaries $(34.69 \%)$. However, a majority of $28.57 \%$ thought that hackings into sensitive customer and company data was less likely.

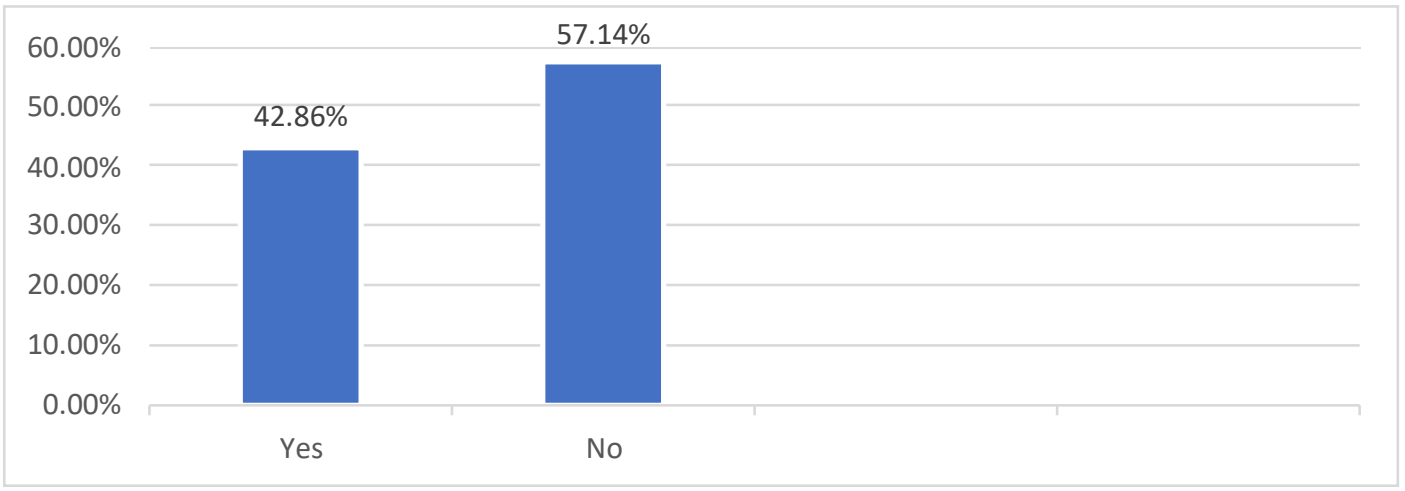

Figure 4.7: Sufficiency of Existing Regulatory Framework to Guarantee Security of Uber Taxi Users

The respondents were asked whether they felt that the existing regulatory framework on transportation sector and security was sufficient to guarantee security of Uber Taxi services users. From Figure 4.7 above, majority of the respondents (57.14\%) felt that the existing 
International Journal of Security, Privacy and Trust Management (IJSPTM) Vol 8, No 3, August 2019

regulatory framework was not sufficient to guarantee security of Uber users. Conversely, $42.86 \%$ of the respondents agreed that the regulatory framework was sufficient to guarantee security of Uber Taxi Users.

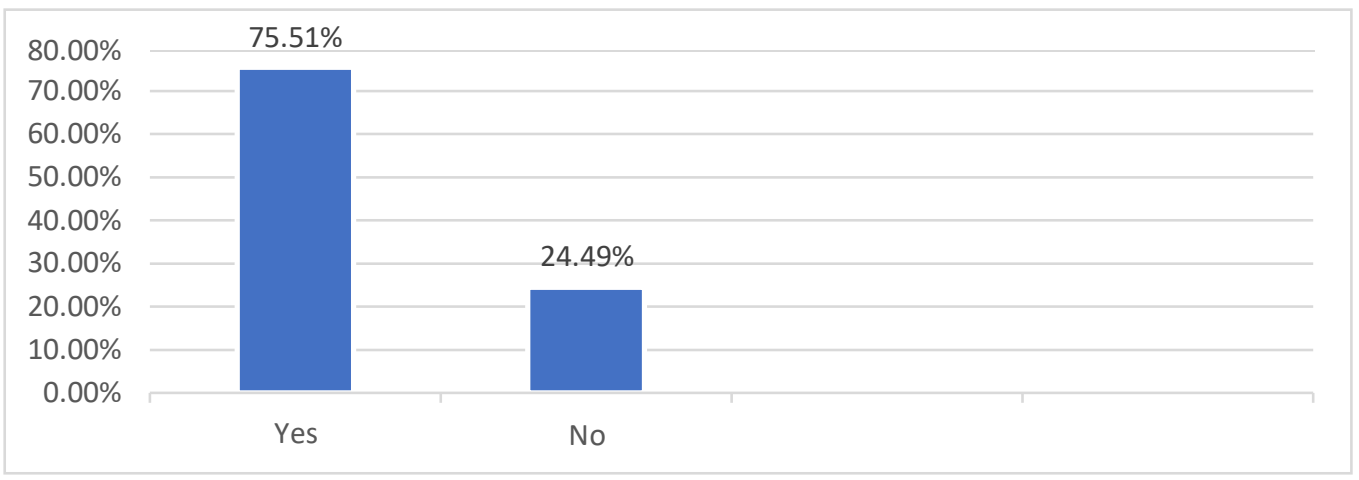

Figure 4.8: Whether e-Hail Taxi Service Providers will take Significant Security Mitigation Measures

The respondents were asked whether they thought e-hail taxi service providers will take significant security mitigation measures as a way to self-regulate. Figure 4.8 above indicate that $75.51 \%$ of the respondents agreed that e-hail Taxi service providers will take significant security mitigation measures while $24.49 \%$ disagreed.

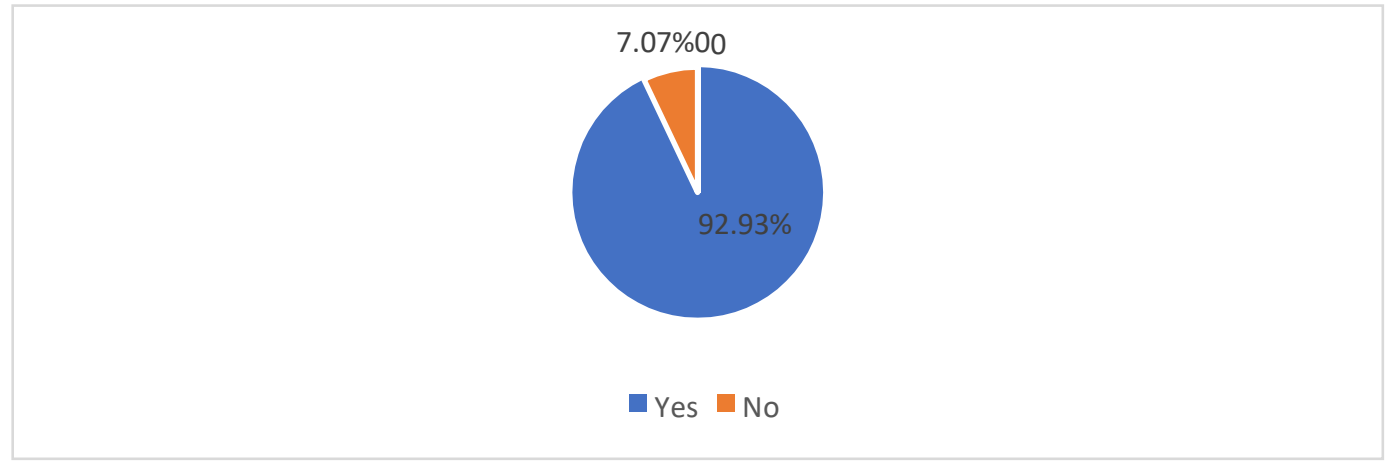

Figure 4.9: Should Relevant Government Authorities do more to Regulate Uber Taxi services

Figure 4.9 above indicates the respondents opinion on whether relevant government agencies should do more in regulating the Uber Taxi Industry. Majority of the respondents $(92.93 \%)$ agreed that the government should take more measures to regulate Uber taxi services while $7.07 \%$ disagreed.

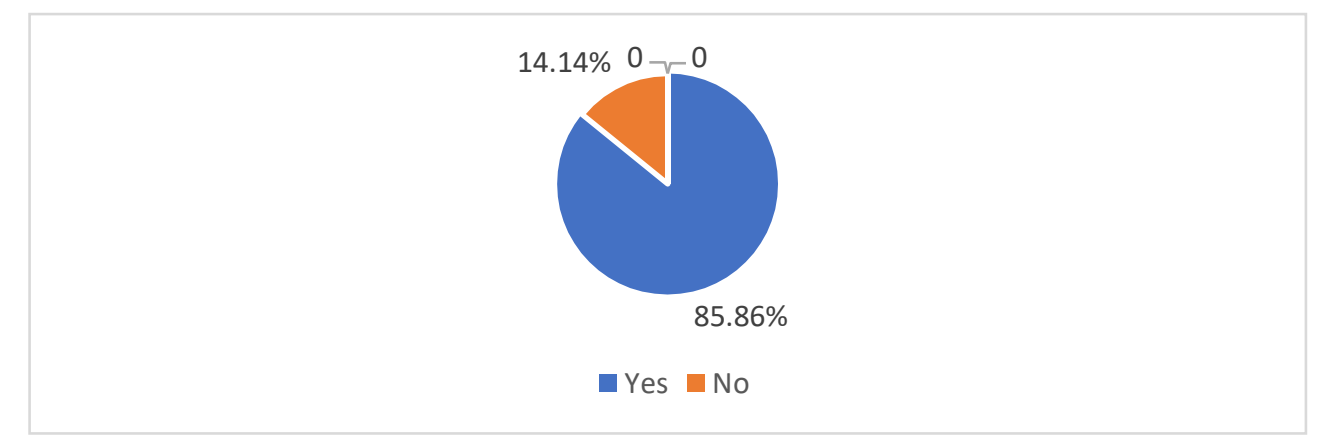

Figure 4.10: Whether Founders and Managers of e-hail Taxi Service Providers should be held accountable for security lapses. 
International Journal of Security, Privacy and Trust Management (IJSPTM) Vol 8, No 3, August 2019

On whether the founders and managers of e-hail taxi service providers should be held accountable for security lapses, Figure 4.10 indicate that $85.86 \%$ of the respondents agreed while $14.14 \%$ disagreed.

\section{Discussion}

The study found out that most people prefer using uber as indicated by Majority of the respondents indicated $32.23 \%$ of the respondents. This is due to the comparative convenience offered by e-hail mode of taxi transportation as affirmed by $58.76 \%$. Besides conveniences, Uber is preferred since is offers employment opportunities for taxi drivers would otherwise be sitting parked in taxi ranks with minimal prospects of getting customers. Also, business opportunities are afforded in this way and in the faster and convenient way that uber tend to deliver commodities such as the case with Uber-eats[10]. This aspect of business and employment opportunities is affirmed by $86.46 \%$ of the respondents.

However, with such significant statistics indicating preference for e-hail taxi services such as Uber, many people are exposed to security risks besides the traditional road safety concerns. As indicated in the study $65.31 \%$ opined that Uber portend security risks to both the drivers of uber taxis who can fall victim to rogue customers and also customers who can fall victim to rogue uber drivers. Some of the security risks that respondents feared to likely occur when taking a uber ride include; abductions (40.82\%), carjacking (40.82\%), sexual harassment $(38.14 \%)$, murders $(35.71 \%)$, robbery $(41.84 \%)$ and burglaries $(34.69 \%)$. All this are security incidents that have been reported to have occurred while using services such as Uber or Lyft. Interestingly, a majority of $28.57 \%$ thought that hackings into sensitive customer and corporate data was less likely.On the one hand, this statistic is likely to be indicative of the lack of information on the extend and effects of such hackings since corporate organisations tend to keep such incidents inhouse as a way of damage control and image protection [2]. On the other hand, such incidents are rare and occur far apart.

The existing regulatory framework in both the security sector and transport sector are not keeping up with the fast evolution of technology. This trying to apply them to current evolved situations is self-defeating since they will definitely be insufficient in address the new dynamics [7; 4]. This view is supported by $57.14 \%$ of the respondents who felt that the existing regulatory framework for app-based taxi hailing system were not sufficient to guarantee safety security. Despite this, $75.51 \%$ of the respondents tended to be optimistic that e-hail transport industry will take meaningful security mitigation measures from the lessons they have learned.However, this is optimism tends to be false since $92.93 \%$ of the respondents felt that government authorities should do more in regulating app-based services such Uber despite the positive outlook on Uber self-regulation.

The issue of accountability especially uber company has been a contentious issue with claims the uber app is just a facilitator and thus not responsible for any security incidents that may befall drivers or customers [5]. This is an escapist excuse since the fact that uber makes it easier to connect taxis to customers is the same way they make easier for rogue elements to access their victims. Therefore, business and security wisdom would require due diligence to be conducted as part of the 'duty of care' that all the players owe to the drivers and customers of uber. It is immoral to continue receiving monetary benefits from transactions that increasingly put peoples' lives at risk yet one is not taking the necessary precautions. Security precautions can only be taken by an entity with a security culture [25]; whose operations revolve around security as indicated by the security atom model in figure 2.1 . Failure in security due diligence requires appropriated judicial action as affirmed by $85.86 \%$ of the respondents who felt that the founders and managers of e-hail taxi services should be held responsible for security lapses. 
International Journal of Security, Privacy and Trust Management (IJSPTM) Vol 8, No 3, August 2019

\section{Conclusions}

While lauding the impressive improvements in transportation that comes with tech-based apps, this study points out to the need to take reasonable security precautions in order to reduce security risks to as low as reasonably possible(ALARP). This is in realisation of the fact that every undertaking is not risk free, and with the consideration that security incidents involving Uber have occurred. Whereas the study did not attempt to establish whether security consideration were factored in during the conception and operationalization of the app-based taxi hailing services, it does however note that the security lapses and reactionary mitigative approaches are indicative of lack of such considerations; and thus concludes that there were security gaps in the conceptualization, development, launch and operationalization of the Uber and other app-based taxi hailing services. Therefore, what the tech-based service providers are reactionary and retrofit attempts to patch-up for the security failures. Unfortunately, it is being done consequent to loss of lives, property and tremendous psychological anguish to the unfortunate victims.

\section{RECOMMENDATIONS}

Based on the findings of the study, the following recommendations are thus put forward:

i. A review of exiting security measures applied to Uber services and other app-based taxi hailing services(even other sharing economies including Airbnb). This should be in the form of a comprehensive security risk analysis leading to development of security plan that is amenable to review to keep pace with the inherent industry dynamics.

ii. Existing regulations in the transport and security sectors need to be aligned with the developments of app-based taxi hailing services and the sharing economy in general. The regulations should spell out the burden of responsibility to be shouldered by the government, developers and managers of app-based taxi hailing services and sharing economies, taxi drivers, and even customers in ensuring the ALARP security point is attained.

\section{Areas for further study}

The study recommends that research should be conduct in the following aspects:

I. Security impact of the risk portended by e-Hail Taxi services and sharing economy.

II. Responsibility ofparties in app-based taxi service providers in mitigation of security risks.

III. A review of the conceptualisation and operationalization of app-based taxi service providers and sharing economy to establish the place of security considerations.

\section{REFERENCES}

[1] Geist, M. (2018). The Sharing Economy and Trade Agreements: The Challenge to Domestic Regulation. In D. McKee, F. Makela, \& T. Scassa (Eds.), Law and the "Sharing Economy": Regulating Online Market Platforms (pp. 223-260). Ottawa: University of Ottawa Press.

[2] Business Insider. (2017). Businesses using Uber are exposed to a security risk that could leak sensitive data. Retrieved April 15, 2019, from www.businessinsider.com: https://www.businessinsider.com/businesses-using-uber-are-exposed-to-a-security-risk-that-couldleak-sensitive-data-2017-8?IR=T 
International Journal of Security, Privacy and Trust Management (IJSPTM) Vol 8, No 3, August 2019

[3] Calo, R., \& Rosenblat, A. (2017). THE TAKING ECONOMY: UBER, INFORMATION, AND POWER. Columbia Law Review, 117(6), 1623-1690.

[4] Riley, J. (2017). Brand New 'Sharing' or Plain Old 'Sweating'?: A Proposal for Regulating the New 'Gig Economy. In R. LEVY, M. O’BRIEN, S. RICE, P. RIDGE, \& MARGARETTHORNTON (Eds.), New Directions for Law in Australia: Essays in Contemporary Law Reform (pp. 59-70). ANU Press.

[5] Tucker, E. (2018). Uber and the Unmaking and Remaking of Taxi Capitalisms: Technology, Law, and Resistance in Historical Perspective. In D. McKee, F. Makela, \& T. Scassa (Eds.), Law and the "Sharing Economy": Regulating Online Market Platforms (pp. 357-392). Ottawa: University of Ottawa Press.

[6] Kamais, C. E. (2019). Complacency and Security Management Practices in Nairobi City County, Kenya. American Journal of Humanities and Social Sciences Research (AJHSSR), 3(4), 01-13.

[7] Escande-Varniol, M.-C. (2018). The Legal Framework for Digital Platform Work: The French Experience. In D. McKee, F. Makela, \& T. Scassa (Eds.), Law and the "Sharing Economy": Regulating Online Market Platforms (pp. 321-356). Ottawa: University of Ottawa Press.

[8] Cassar, L., \& Meier, S. (2018). Nonmonetary Incentives and the Implications of Work as a Source of Meaning. The Journal of Economic Perspectives, 32(3), 215-238.

[9] Blystone, D. (2019). The Story of Uber. Retrieved April 22, 2019, from www.investopedia.: https://www.investopedia.com/articles/personal-finance/111015/story-uber.asp

[10] Jalloh, M. S. (2019). Uber: Advantages and Disadvantages. Retrieved April 15, 2019, from www.investopedia.com: https://www.investopedia.com/articles/investing/110614/taxi-industry-proscons-uber-and-other-ehail-apps.asp

[11] Scheiber, N. (2017). Uber to Repay Millions to Drivers, Who Could Be Owed Far More. Retrieved April 24, 2019, from ww.nytimes.com: https://www.nytimes.com/2017/05/23/business/economy/uber-drivers-tax.html?_r=0

[12] Sun, T., \& Bao, B. (2018). Lime's Next Chapter In Smart Mobility Backed By GV And Uber. Retrieved April 24, 2019, from www.li.me: https:/www.li.me/second-street/lime-smart-mobilitybacked-by-gv-uber

[13] Dickey, M. R. (2018). Uber acquires bike-share startup JUMP. Retrieved April 24, 2019, from techcrunch.com: https://techcrunch.com/2018/04/09/uber-acquires-bike-share-startup-jump/

[14] Sweeney, M. M., \& Perliger, A. (2018). Explaining the Spontaneous Nature of Far-Right Violence in the United States. Perspectives on Terrorism, 12(6), 52-71.

[15] Alastair. (2015). Uber Kenya Launch Party. Retrieved April 29, 2019, from Uber Website: https://www.uber.com/en-KE/blog/uber-kenya-launch-party/

[16] Reuters. (2016). Uber driver attacked in Kenya, his taxi torched: police. Retrieved April 29, 2019, from www.reuters.com: https://www.reuters.com/article/us-kenya-security/uber-driver-attacked-inkenya-his-taxi-torched-police-idUSKCNOVV19X

[17] The Crimson Editorial Board. (2019). New Uber Feature Promises Physical Safety, Data Risks. Retrieved April 15, 2019, from www.thecrimson.com: https://www.thecrimson.com/article/2019/2/11/editorial-uber-feature-safety-data/ 
International Journal of Security, Privacy and Trust Management (IJSPTM) Vol 8, No 3, August 2019

[18] State of NSW Department of Finance, Services and Innovation. (2015). The Collaborative Economy in NSW - A Position Paper. Retrieved from NSW State website: http://www.finance.nsw.gov.au/publication-and-resources/collaborative-economy

[19] Dwyer, K. (2018). Uber for Business: More Dangerous Than We Realized. Retrieved April 15, 2019, from https://riskandinsurance.com/uber-for-business-critical-risks-to-consider-beforerequesting-a-ride/

[20] Uber Newsroom. (2017). 2016 Data Security Incident. Retrieved April 15, 2019, from www.uber.com: https://www.uber.com/newsroom/2016-data-incident/

[21] Washington Post. (2019). Woman killed after getting into what she thought was an Uber. Retrieved April 28, 2019, from www.washingtonpost.com: https://www.washingtonpost.com/crimelaw/2019/03/31/she-thought-she-had-gotten-into-her-uber-police-say-hours-later-hunters-found-herbody/

[22] Hoodline. (2017). Uber Driver Remains Missing After Car Is Found In Bayview. Retrieved April 28, 2019, from hoodline.com: ttps://hoodline.com/2017/05/uber-driver-remains-missing-after-car-isfound-in-bayview

[23] NBC News. (2019). Uber Driver Disappears After Picking Up Passenger in DC. Retrieved April 28, 2019, from www.nbcwashington.com: https://www.nbcwashington.com/news/local/Uber-DriverDisappears-After-Picking-Up-Passenger-in-DC_Washington-DC-505228392.html

[24] Dahir, A. L. (2017). Uber drivers in Kenya will take selfies to keep riders safe. Retrieved April 29, 2019, from Quartz Africa Website: https://qz.com/africa/1019010/uber-is-introducing-live-facechecks-in-kenya-to-reduce-driver-fraud/

[25] Purpura, P. P. (2013). Foundations of Security and Loss Prevention. In P. P. Purpura, Security and Loss Prevention (6 ed., pp. 661-705). Butterworth: Heinemann. doi:https://doi.org/10.1016/C20100-69612-X

[26] Huffington Post. (2019). Uber Driver Burglarized Home After Dropping Customers Off At Airport, Police Say. (H. Miller, Producer) Retrieved April 28, 2019, from www.huffpost.com: https://www.huffpost.com/entry/uber-driver-robs-passengers-home_n_5cadda32e4b0d6eb63c24e54

[27] Atchsion Transportation Services . (2017). REPORTED LIST OF INCIDENTS INVOLVING UBER AND LYFT. Retrieved from www.atchisontransport.com: https://www.atchisontransport.com/blog/reported-list-of-incidents-involving-uber-and-lyft/

[28] Kothari, C. R. (2004). Research Methodology: Methods and Techniques (2 ed.). New Delhi: New Age International Publishers.

\section{AUTHOR}

Cosmas Ekwom Kamais ${ }^{1}$ is Masters Candidate (Security Management) at the Egerton University, Kenya. He is also undertaking Masters in Peace and Security Management at Kenyatta University Kenya. He holds a BSc in Military Science from Egerton University and Postgraduate Level 6 Diploma in Certified Security Management Professional (CSMP) from the International Security Management Institute, United Kingdom (ISMI). He is also Member of ISMI (M. ISMI).

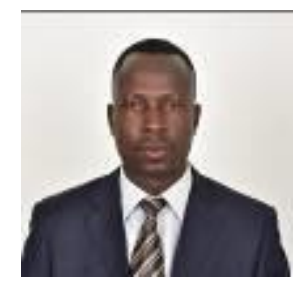

